1

2

3

4

5

6

7

8

9

\title{
Phenolic distribution in apple epidermal and outer cortex tissue by multispectral deep-UV autofluorescence cryo-imaging
}

\section{Authors:}

Kevin Vidot ${ }^{\mathrm{a}, \mathrm{b}}$ (kevin.vidot@inra.fr), Marie-Françoise Devaux ${ }^{\mathrm{a}}$ (mailto:mariefrancoise.devaux@inra.fr), Camille Alvarado ${ }^{\mathrm{a}}$ (camille.alvarado@inra.fr),Sylvain Guyot ${ }^{\mathrm{c}}$ (sylvain.guyot@inra.fr), Frederic Jamme ${ }^{\mathrm{d}}$ (frederic.jamme@ @ynchrotron-soleil.fr), Cédric Gaillard $^{\mathrm{a}}$ (cedric.gaillard@inra.fr), René Siret ${ }^{\mathrm{b}}$ (r.siret@groupe-esa.com), Marc Lahaye $\mathrm{a}^{\mathrm{a}^{*}}$ (1) (marc.lahaye@inra.fr)

\section{Affiliations :}

${ }^{a}$ UR 1268 Biopolymères Interactions Assemblages, équipe Paroi Végétale et Polysaccharides Pariétaux (PVPP), INRA, 44300 Nantes, France

b USC 1422 GRAPPE, INRA, Ecole Supérieure d'Agricultures, SFR 4207 QUASAV, 49100 Angers, France

${ }^{\mathrm{c}}$ UR 1268 Biopolymères Interactions Assemblages, équipe Polyphénols, Réactivité, Procédés (PRP), INRA, 35653 Le Rheu, France

${ }^{\mathrm{d}}$ Synchrotron SOLEIL, L'Orme des Merisiers, Saint-Aubin, 91192 Gif-sur-Yvette Cedex, France

\section{Corresponding author:}

2 Marc Lahaye: marc.lahaye@inra.fr 


\section{Abstract}

Phenolic compounds in fruit are involved in responses to biotic and abiotic stresses and are responsible for organoleptic properties. To establish the distribution of these secondary metabolites at the tissue and sub-cellular scales, mapping of fluorescence in apple epidermis and outer cortex tissue in cryogenic condition was performed after deep-UV excitation at 275 nm. Douce Moën and Guillevic cider apple varieties were sampled and frozen after harvest, after 30 days at $4{ }^{\circ} \mathrm{C}$ and after 20 days at room temperature. Image analysis of fluorescence emission images acquired between 300 and $650 \mathrm{~nm}$ allowed the assignment of fluorescence signals to phenolic compound families based on reference molecules. Emission attributed to monomeric and/or condensed flavanol was localized in whole tissue with major fluorescence in the cuticle region. Hydroxycinnamic acids were found predominantly in the outer cortex and appeared in the cell wall. Fluorescent pigments were mostly found in the epidermis. The distribution of flavanols in the sub-cuticle and phenolic acids in the outer cortex distinguished apple varieties. Storage conditions had no impact on phenolic distribution. The proposed fluorescent imaging and analysis approach enables studies on phenolic distribution in relation to fruit development, biotic/abiotic stress resistance and quality.

Key words: Malus domestica, phenolic compounds, autofluorescence, multispectral imaging, deep-UV synchrotron light, cryo-microscopy. 


\section{Introduction}

Phenolic compounds are common plant secondary metabolites that have been grouped into three classes: flavonoids, phenolic acids and stilbenes [1]. The flavonoids encompass flavanols that are also found as oligomers and polymers (i.e., proanthocyanidins and condensed tannins), anthocyanins and flavonols, while phenolic acids comprise hydroxybenzoic acids and hydroxycinnamic acids (Figure 1). Except for flavanols and hydroxybenzoic acids, which are mainly present in their free form, most phenolic compounds are glycosylated and/or acylated derivatives. Their ultraviolet absorption capacity limits lightinduced damage to tissues while they are part of plant defence mechanisms against external biotic stresses [2, 3]. In fleshy fruit, phenolic compounds are known for their antioxidant contribution to foods and organoleptic properties, such as colour, astringency or bitterness [46]. Various studies in apple and grape have shown important differences in phenolic content between varieties according to fruit development and tissue [7]. Phenolic compounds are commonly characterized by biochemical techniques on whole fruit, skin, flesh, seed or juice extracts. However, there are few reports on the distribution of specific phenolic compounds at the tissue and sub-cellular scales under in-vivo-like conditions. Flavanols and condensed tannins were determined to be localized in the epidermis, parenchyma and seeds by microscopy of fresh or chemically fixed apple [8], grape [9, 10] and other fruits [11-14]. Flavanols were localized by DMACA staining (4-dimethylaminocinnamaldehyde) [14-16] while flavonols were highlighted by fluorescence microscopy using the specific dye DPBA (diphenylboric acid-2-aminoethyl ester) [17, 18]. However, chemical preparation damage to fleshy fruit tissue integrity affects the cellular localization of diffusible compounds [19], and dyes are limited by their specificities.

To address these issues, mapping phenolic compounds through their autofluorescence characteristics appears to be a good alternative as no specific stain is required. 
Hydroxycinnamic acids express a blue fluorescence when excited at the UV wavelength of approximately $350 \mathrm{~nm}[20,21]$ while anthocyanins and flavonols are autofluorescent at visible wavelengths [22]. Monomeric and condensed tannin $((+)$ catechin, (-)epi-catechin, procyanidins) fluorescence requires deep-UV wavelength excitation at approximately $280 \mathrm{~nm}$ [23] [24]. The use of different bandpass filters to select specific ranges of fluorescence emissions offers the opportunity to localize different compounds within the same sample through a multispectral approach [25]. However, data on the fluorescence emission of specific phenolic compounds are scarce due to the high number of entities that constitute this metabolite family and because access to pure reference phenolic compounds is limited.

To avoid artefacts related to small compound diffusion and loss during sample preparation, cryo-fixation, cryo-microtomy and fluorescence cryo-observation of biological samples have seen recent developments. Cryo-confocal observations at high resolutions were introduced with the realization of specific microscope stages and immersion objective lens prototypes [26, 27]. A simpler and readily accessible setup was developed to observe fleshy fruit tissue by cryo-laser scanning confocal microscopy (LSCM) [18]. Among the advantages of cryo-observations is the lower fluorescence bleaching compared to that during room temperature observations and thus the recovery of higher fluorescence intensity $[26,28]$.

Preliminary tests of fresh fruit auto-fluorescence responses after excitation at $375 \mathrm{~nm}$ were performed on apple and grape. The latter revealed promising autofluorescence signals, while a lower excitation wavelength was found necessary to assess flavanol localization. The objective of the present work was to map phenolic compounds in cryo-fixed outer tissues of apple. The mapping was performed at a large field of view by multispectral autofluorescence imaging after deep-UV excitation at $275 \mathrm{~nm}$ using the setup developed for fleshy fruit cryoobservation. Two cider apple varieties stored in three different conditions were studied to evaluate the genetic and physiological impacts on phenolic compound distribution. 
Fluorescence excitation and emission characteristics of reference phenolic compounds were recorded to help identify fruit tissue phenolics.

\section{Materials and methods}

\subsection{Materials}

\subsubsection{Chemicals}

Phenolic compounds used for reference fluorescence spectra were from the laboratory collections of ESA-GRAPPE (Angers, France) and BIA-PRP (Rennes, France). Formic acid was purchased from Sigma-Aldrich (UK) and methanol was purchased from CarloErba (Italy).

\subsubsection{Fruits}

Apple (Malus domestica, Royal Gala) and grape (Vitis vinifera, Red Italian) for preliminary fluorescence analysis after $375 \mathrm{~nm}$ UV excitation were from a local retail store. These fruits were used without further storage. For the fluorescence mapping following excitation at $275 \mathrm{~nm}$, two cider apple varieties, Douce Moën (M. domestica, Douce Moën) and Guillevic (M. domestica, Guillevic), were provided by IFPC (Le Rheu, France). Fruits were harvested on October 2017 in orchards at Surzur (Morbihan, France). Nine fruits of each variety were subjected to three different storage conditions: three were immediately sampled, three were stored at $4{ }^{\circ} \mathrm{C}$ for 30 days and three were stored at room temperature for 20 days before sampling.

\subsection{Methods}

\subsubsection{Spectrofluorometry}

Phenolic references were dissolved at $2 \mathrm{mg} \mathrm{mL}^{-1}$ in $2 \mathrm{~mL}$ of $\mathrm{H}_{2} \mathrm{O}: \mathrm{MeOH}(1: 1$ in volume) $+1 \%$ formic acid (in volume). Quartz cuvettes (10 x $4 \mathrm{~mm}, 114 \mathrm{~F}-\mathrm{QS}$, Suprasil 
HELLMA Analytics, France) were filled with $500 \mu \mathrm{L}$ of standard solution and observed by spectrofluorimetry (F-4500, HITACHI, Japan). Emission and excitation spectra for each compound were recorded between $200 \mathrm{~nm}$ and $600 \mathrm{~nm}$.

\subsubsection{Laser scanning confocal microscopy (LSCM)}

Cubes of $5 \times 5 \times 5 \mathrm{~mm}^{3}$ were sampled from the epidermal region of equatorial fruit slices of commercial apple and grape. Sections of $100 \mu \mathrm{m}$ thickness were cut from fresh cubes with a vibrating blade microtome (HM 650V, MICROM, France) and immediately observed or dipped in standard buffer solution pH 10 (HI 70010C, NIST standard, HANNA INSTRUMENTS, Hungary) followed by $\mathrm{H}_{2} \mathrm{O}$ milliQ wash prior to LSCM observations at room temperature. LSCM (A1 Eclipse Ti inverted microscope, NIKON Inc., Japan) was configured with laser diode excitation at $375 \mathrm{~nm}$. Fluorescence emission was acquired at 20x magnification with a resolution of $0.63 \mu \mathrm{mpixel}^{-1}$ and image size of $512 \times 512$ pixels $^{2}$ (16bit). Four bandpass emission filters were used to map fluorescence: $400-450 \mathrm{~nm}, 500-530 \mathrm{~nm}$, 560-600 nm and 630-700 nm. These form sets of multispectral images of four channels with spectral controlled excitation and emission parameters.

\subsubsection{Synchrotron deep-UV wide-field fluorescence microscopy (DUV)}

One $5 \times 5 \times 5 \mathrm{~mm}^{3}$ cube was randomly sampled from the epidermal region of a cider apple fruit equatorial slice. The cube was frozen in liquid nitrogen-cooled isopentane and stored at $-20{ }^{\circ} \mathrm{C}$ prior to analysis. Sections $(60 \mu \mathrm{m}$ thick $)$ were cut from frozen cubes using a cryostat microtome (HM $500 \mathrm{OM}, \mathrm{MICROM}$, France) at $-20^{\circ} \mathrm{C}$. The section was placed between quartz lamella (R52-5000, ESCO Optics, USA) glued together by frozen water droplets. Synchrotron UV microscopy was performed at the DISCO (Dichroism, Imaging, mass Spectrometry for Chemistry and biOlogy) beamline at the SOLEIL (Source Optimisée de Lumière à Energie Intermédiaire du LURE (Laboratoire à Utilisation du Rayonnement 
Electromagnétique)) synchrotron radiation facility [29] (Gif-sur-Yvette, Saint-Aubin, France) on the inverted epi-fluorescence TELEMOS microscope [30]. Observation was realized under cryogenic conditions using a handmade setup composed of a Peltier stage (PE100, LINKAM Scientifics, UK) cooled by dry ice as described in [18]. The wide-field microscope TELEMOS modified by the DISCO beamline staff was a Zeiss Axio Observer Z-1 designed 144 to observe samples after deep-UV (DUV) excitation. The microscope was equipped with a 145 motorized sample plate (MS-2000 XY, Applied Scientific Instrument, USA) to move the sample along the $\mathrm{X}$ and $\mathrm{Y}$ axes. Sample movement along the $\mathrm{Z}$ axis was controlled by the inverted microscope. The setup used the 10× magnification Zeiss Ultrafluar lens (N.A 0.2, WD 7.4) and a sharp $300 \mathrm{~nm}$ dichroic mirror "DM" (Omega Optical), which reflected the 280 $149 \mathrm{~nm}$ excitation and transmitted emission light above $300 \mathrm{~nm}$. Multispectral fluorescence 150 emission was recorded using six different emission bandpass filters: 300-306 nm, 327-353 151 nm, 352-388 nm, 412-438 nm, 420-480 nm and 600-650 nm (Semrock, Rochester, USA). In the text, filters are referred to by their low wavelength limit. A back-illuminated CCD camera (Pixis BUV, Princeton Instrument, USA) recorded the images (1024 x 1024 pixels; 1 x $1 \mu \mathrm{m}^{2}$ 154 per pixel; grey level coded in 16 bit). Acquisition times were $12.5 \mathrm{~s}$ for the $300 \mathrm{~nm}$ filter, $5 \mathrm{~s}$ 155 for the 327, 352, 412 and $420 \mathrm{~nm}$ filters, and $7.5 \mathrm{~s}$ for the $600 \mathrm{~nm}$ filter. Acquisition was 156 performed from the sample cuticle to approximately one $\mathrm{mm}$ inside the tissue. With three 157 biological repetitions and three different storage modalities, a total of nine images were 158 registered per variety. The beamline intensity, which was focused at the centre of the observation field, led to 160 raw images that required corrections to homogenize illumination. In addition, the camera 161 provided a non-null background without illumination. Both inhomogeneous illumination and 162 background corrections were realized according to the following formula: 


$$
\text { Ic }=\frac{I-\text { Dark }}{\text { White }- \text { Dark }}
$$
is the flat field

For this purpose, nine different "dark" images were recorded without sample and without any 167 illumination, one for each of the six emission filters. The "White" images were acquired using 168 a frame $\left(1.0 \times 1.0 \mathrm{~cm}^{2}\right.$, AB-0576, Gene Frame, THERMOSCIENTIFIC, UK) displaying a homogeneous autofluorescent signal. Thresholding was also required to define the sample image from the camera noise. Image pretreatments were performed using MATLAB® 2017b. sample image area. To take into account out-of-plane sample sections, several acquisitions were recorded for the same sample area with a maximum of six focal planes. As this method was not confocal imaging, a clear image was reconstructed by combining the different focal plane views with the extended focus software HeliconFocus6® (version 6.8.0) using the pyramidal method.

\subsubsection{Multispectral analysis of DUV fluorescence images}

DUV fluorescence emission was valued based on the grey scale intensity of pixels in cropped images. Principal component analysis was applied separately on each multispectral image, and fluorescence profiles were extracted from selected emission filters.

\subsubsection{Image Analysis}

184 filters and $\mathrm{n}$ rows corresponding to the $\mathrm{n}$ pixels of the image. Principal component analysis

185 (PCA) was applied to the resulting data table, and correlation circles were drawn from the 
186 PCA loadings. Principal component images were obtained by refolding scores [31].

187 Component images were filtered to keep $99 \%$ of pixels closer to the median value and to 188 remove eventual aberrant pixel values prior to normalization of grey levels between 0 and

189

190

191

192

193

194 255. PCA reconstructed colour images were created from components 1,2 and 3 identified in the blue, red and green channels, respectively.

Localization of phenolic compounds in samples was also analysed by computing fluorescence intensity profiles from the cuticle to the inner tissue. This "image distance" analysis was realized using FIJI/ImageJ® software [32] and the mathematical morphology plugin process/erode (3D) [33]. Thresholding was first applied to create a binary mask of the sample. Distance from the cuticle was obtained by the following procedure: one-pixel erosion (pixel size $=1 \times 1 \mu \mathrm{m}^{2}$ ) was applied to the sample mask and the resulting binary image was subtracted from the initial sample binary image. This step was iteratively applied until the last image column was reached. The mean profile was smoothed to reduce intensity variations due to the presence of cell lumens with low fluorescence and cell walls with high fluorescence. This was realized by applying local regression (LOESS) with a degree of smoothing of 0.4 . Normalization between 0 and 1 was realized on the maximum smoothed mean value to allow profiles comparison between samples. Examples of raw and smoothed profiles are shown for Douce Moën at harvest in Supplementary Figures 1 and 2. The smoothed profiles from the three biological replicates per storage modality were averaged and the mean profile per modality was plotted with its 95\% confident interval (Supplementary Figure 3).

\subsubsection{Statistical analyses}

The effect of storage was evaluated by Student's t-tests of the smoothed mean pixel values of three biological replicates per pixel distance. As no significant differences were found between storage modalities, Student's t-test for variety effect was performed on the nine replicates. 

in $\mathrm{R}$ [34].

\section{Results}

\subsection{Fluorescence properties of reference phenolic compound}

Excitation and emission fluorescence spectra were registered from standard phenolic compounds (Supplementary figure 4) and the maximum wavelength responses recorded

(Table 1). If associating specific compounds with peculiar emission wavelengths is difficult due to the width of spectra with large overlaps, distinguishing families of compounds, such as flavanols (including condensed tannins), phenolic acids, anthocyanins and flavonols remains possible. For example, phenolic acids, such as p-coumaric acid, ferulic acid and caffeic acid have a maximum emission at approximately $420 \mathrm{~nm}$, while flavanols such as (+) catechin, (-) epi-catechin and procyanidin share maximum emission at approximately $320 \mathrm{~nm}$. In fact, due to their large excitation spectra, most phenolic compounds will fluoresce under excitation at $275 \mathrm{~nm}$. Among the tested reference compounds, only phloridzin, rutin and arbutin will not 225 fluoresce after deep-UV excitation.

\subsection{Preliminary analysis of autofluorescence observed after excitation at $375 \mathrm{~nm}$}

In a preliminary study, autofluorescence observations of fleshy fruit were realized with a

228 laboratory confocal laser scanning microscope using a UV diode laser at $375 \mathrm{~nm}$. This test 229 was performed to check the pertinence of autofluorescence analysis on two types of fleshy 230 fruits: Royal Gala apple and Italian Red grape. In all cases, the cuticle presented bright and 231 intense fluorescence as previously observed [35]. Red spots were observed within the cells of 232 both fruit but particularly in grape, while light yellow fluorescence was observed in vacuole233 like compartments only in apple. Red fluorescence could correspond to chlorophyll residues 234 while yellow emission could be related to compounds of the flavonol class, such as quercetin 
derivatives [36] [37]. A weak blue emission was also observed in the cell wall at native $\mathrm{pH}$ and was found to increase at $\mathrm{pH} 10$, as reported for ferulic or coumaric acids [20]. These emission variations after UV excitation at $375 \mathrm{~nm}$ provided support for the mapping of phenolic compounds using multispectral autofluorescence imaging. However, a lower excitation wavelength was sought to access compounds in the flavanol family.

\subsection{Autofluorescence after excitation at $275 \mathrm{~nm}$}

The autofluorescence of flavanols in fleshy fruit tissue requires excitation at a low UV wavelength, which is yet inaccessible with a common microscopy laser beam. The synchrotron beamline at DISCO allows for exciting samples in the 200-350 nm range. To limit the diffusion of phenolic compounds, apple tissue was first cryo-fixed prior to cryoobservation of multispectral fluorescence from $300 \mathrm{~nm}$ to $650 \mathrm{~nm}$ (Figure 3). Outer-cortex parenchyma fluorescence was distinguished from that of epidermal tissue, which encompasses cuticle and sub-cuticular cell layers (Figure 3). Between 327 and $388 \mathrm{~nm}$, subcuticular cell layer fluorescence was more intense and disappeared at higher bandpass wavelength filters except, for the $600 \mathrm{~nm}$ filter. Intense fluorescent spots were observed inside the cell mainly with 300 and $327 \mathrm{~nm}$ filters, but in all cases, cells walls showed a more intense signal than cells.

To better distinguish differences in sample fluorescence, principal component analysis was applied to the collection of images obtained with the different bandpass filters. All principal component analyses performed on the three modalities presented similar loadings. For example, the loading and component images are shown in Figure 4 for representative samples of Douce Moën and Guillevic apple varieties at harvest. Fluorescence through 300, 327, 352, 412, 420 and $600 \mathrm{~nm}$ filters contributed mainly to components 1 and 2 and fluorescence at 300, 327 and $600 \mathrm{~nm}$ contributed more weakly to components 3 and 4 . Most filters contributed to component 1 , which corresponded to the general variations of 
fluorescence intensity and explained $65.8 \%$ and $61.7 \%$ of the total variance for Douce Moën

261 and Guillevic, respectively. The component images showed that the highest overall

262 fluorescence intensity was mainly localized in the walls of outer-cortical cells. The second

263 component, expressing the contribution of the 300 and $327 \mathrm{~nm}$ filters (positive side) in

264 opposition to the emission filters 412 and $420 \mathrm{~nm}$ (negative side), contrasted the sub-cuticular

265 cell layers. Filters 352 and $600 \mathrm{~nm}$ were inversely related to this second component for the

266 two varieties. The third component pointed out the cuticle region with a relatively higher

267 fluorescence measured using the $327 \mathrm{~nm}$ emission filter (in red) compared to the 300 and 600

$268 \mathrm{~nm}$ filters (in blue), showing the rest of the sample. The fourth component showed a higher

269 level of noise and a relatively higher fluorescence level associated with the $300 \mathrm{~nm}$ filter (in

270 blue) in the epidermal region as well as in the cell walls of sub-cuticular cells and outer

271 cortical cells. Thus, fluorescence distinguished three areas: the cuticle region with a relatively

272 higher fluorescence emission using the $327 \mathrm{~nm}$ filter, the sub-cuticular cell layers with the

$273300 \mathrm{~nm}$ and $600 \mathrm{~nm}$ filters, and the walls of outer-cortical cells with the 352, 412 and $420 \mathrm{~nm}$

274 filters. The three first component images of the representative samples were combined in an

275 RGB image to better visualize the tissue regions according to fluorescence (Figure 4). To

276 objectivize differences observed in fluorescence distribution, normalized intensity profiles for

277 all images of the two varieties at the different storage conditions were measured.

Intensity profiles from the cuticular to the outer cortical tissue were obtained for the

279 four bandpass filters discriminating the most apple tissues: 300, 327, 420 and $600 \mathrm{~nm}$. As cell

280 lumen and cell walls showed marked differences in fluorescence intensities, smoothing of

281 each profile was realized by local regression (LOESS) at the expense of fine structures

282 contributing to fluorescence (cells, cell walls, sub-cellular structures). The smoothed and

283 normalized curves allowed comparison of trends in fluorescence variations along the first 400

$284 \mu \mathrm{m}$ under the cuticle. Examples of raw and smoothed profiles are shown for the Douce Moën 
variety at harvest in Supplementary Figures 1 and 2. Considering close fruit calibres within varieties, Student's t-test at each distance point per filter showed that storage modalities had no effect on fluorescence profiles (p-value > 0.05; Supplementary Figure 3). Thus, all biological replicates $(n=9)$ were used to evaluate the effect of apple varieties on fluorescence intensity profiles. Significant differences were particularly noted with the $327 \mathrm{~nm}$ and $420 \mathrm{~nm}$ filters (Figure 5). For the 327 filter, an inverse gradient was observed between the two varieties with a rupture point at approximately $100 \mu \mathrm{m}$ from the cuticle. Douce Moën showed higher fluorescence intensity than Guillevic, particularly in the first $10 \mu \mathrm{m}$ under the cuticle but was lower than that of Guillevic $60 \mu \mathrm{m}$ away from the cuticle. The $420 \mathrm{~nm}$ filter also presented two significantly different areas, first in the epidermis where the Guillevic signal was higher than that of Douce Moën and opposite to the $327 \mathrm{~nm}$ filter profile and second in the outer cortex (300 to the $400 \mu \mathrm{m}$ limit of the images) where Guillevic fluorescence was lower. A maximum was observed at approximately $100 \mu \mathrm{m}$ for Guillevic, while for Douce Moën, it was at approximately $330 \mu \mathrm{m}$ from the cuticle. Weak significant differences were observed between Guillevic and Douce Moën in the sub-cuticular cell layers for the $300 \mathrm{~nm}$ filter and in the outer cortex for the $600 \mathrm{~nm}$ filter. These two profiles also showed similar ruptures at approximately $75-100 \mu \mathrm{m}$ from the cuticle. The mean smoothed plot profiles (Figure 6) showed good agreement with the fluorescence distribution observed in the representative PCA reconstructed images (Figure 4). The three regions observed may be approximately delimited from these results (Figure 6) for Douce Moën to range from approximately 0 to $50 \mu \mathrm{m}, 50$ to $200 \mu \mathrm{m}$ and $200 \mu \mathrm{m}$ to $400 \mu \mathrm{m}$ while for Guillevic, to range from approximately 0 to $60 \mu \mathrm{m}, 60$ to $150 \mu \mathrm{m}$ and 150 to $400 \mu \mathrm{m}$. These regions may correspond to the cuticle and the sub-cuticle forming the epidermis and the outer cortex as depicted in Figure 3. 
The fluorescence emission of reference phenolic compounds allowed us to propose the possible nature of chemicals in the different tissues (Table 1). Fluorescence observed with the $300 \mathrm{~nm}$ filter was more likely due to proteins as this range of emission is related to the aminoacids tyrosine and phenylalanine [38]. Fluorescence through the $327 \mathrm{~nm}$ filter may have corresponded to the tryptophan and most likely to catechins that are predominant in apple fruit tissue. Since these compounds are flavanol monomers and oligomers, by extension such

315 fluorescence would also reveal condensed tannins. Likewise, fluorescence at $420 \mathrm{~nm}$ would represent the phenolic acid family, such as hydroxycinnamic acids, while the fluorescence at $600 \mathrm{~nm}$ would be pigments, such as anthocyanin or chlorophyll. According to these propositions, pigments would be particularly localized in the sub-cuticular cell layers of both varieties, while flavanols including condensed tannins would be present in the epidermis and outer cortex of both varieties, though with higher intensity in the sub-cuticular cell layers of Guillevic. The distribution of phenolic acids differed markedly between the two varieties. In Douce Moën, they were present mainly in the outer cortex, while in Guillevic they were also present in the sub-cuticular cell layers. Storage conditions did not appear to affect these 324 distributions.

\section{Discussion}

The results showed that multispectral observation of auto-fluorescence provides a convenient alternative for localizing phenolic compound families in fleshy fruit tissue with limited sample preparation and artefact introduction compared to classical resin embedding and staining methods. Adaptation of the cryogenic procedures developed for cryo-LSCM [18] to the wide-field TELEMOS microscope of the DISCO beamline at the SOLEIL synchrotron facility allowed observation of fluorescence from $275 \mathrm{~nm}$, which excited flavanols and

332 condensed tannins together with other phenolic compounds in well-preserved apple tissue 333 with limited metabolite diffusion. The obtained images confirmed the efficiency of the 
cryogenic process as intracellular content appeared filled, though of lower fluorescence intensity compared to cell walls. Cryo-observation also improved fluorescence intensity [26], likely by reducing fluorescent bleaching due to the temperature dependency of quencher diffusion [28]. This phenomenon was particularly helpful in establishing the qualitative distribution of fluorescent compounds in fruit tissue.

Fluorescence tended to indicate phenolic compounds within cell walls. However, most phenolics are localized within cell organelles, vacuoles or the cytoplasm $[39,40]$ with fewer in cell walls. In apple, phenolic compounds have not been described as part of the cell wall polysaccharide composition [41] [42]. Some authors [43] suggested that tannin accumulation takes place in the vacuole, but their polymerization appeared near the cell walls. As apple fruit cells are highly hydrated, ice crystals formed during cryo-fixation of the waterfilled vacuoles [44] may have pushed fluorescent organelles and cytoplasmic materials close to the cell walls. As a consequence, part of the cell wall fluorescence observed with the $10 \times$ magnification lens (resolution: $1.24 \mu \mathrm{m} /$ pixel) may have resulted from nearby intracellular fluorescent compounds/organelles. However, the blue emission observed by LSCM in the cell wall of fresh apple and grape tissue and its increased fluorescence at basic $\mathrm{pH}$ supported the presence of hydroxycinnamic acids in cell walls. This observation was realized at higher magnification $(20 \times$, resolution of $0.63 \mu \mathrm{m} /$ pixel) than that of the TELEMOS setup and excluded the potential of ice crystal effects on cell wall fluorescence. Hydroxycinnamic acids have already been reported in apple fruit mostly in vacuoles due to their characterization in the juice [45] [46, 47], but they are also known to be present in plant cell walls [48]. Their low concentration in apple cell walls likely prevented their detection by classic analytical techniques. However, further work is needed to assess the nature of these compounds and whether they are esters of cell wall polysaccharides, as reported for other plants [20] $[49,50]$. 
LSCM (Figure 2). The observation of cuticle autofluorescence was already reported in several fruits, including apples and grapes and may be related to high concentrations of proteins and phenolic acids [35] [51]. Though anthocyanins, flavonols, flavanols (including condensed tannins), hydroxycinnamic acids and proteins were essentially reported in the epidermis region [52-54], they were more rarely localized in sub-cuticular cell layers $[8,10,14]$. The high concentration of phenolic compounds in the sub-cuticular cell layers is probably related to defence against pathogens [55] or light damage to tissues. The firmer mechanical resistance of grape and apple skins compared to their flesh $[56,57]$ may also be associated to the important presence of phenolic compounds in the skin. Indeed, phenolic compounds and, in 368 particular, flavonoids were proposed to increase the rigidity of the cutin matrix in the cuticle of ripe tomato [58]. Comparatively, excitation with DUV at $275 \mathrm{~nm}$ revealed a lower cuticle autofluorescence. Although flavonoids and phenolic acids, the main cuticle phenolic compounds, have large excitation and emission spectra (Supplementary Figure 4), 275 nm excitation was not optimal to yield high autofluorescence intensities. Though such a 373 wavelength was beneficial for exciting flavanols and proteins fluorescence, it appears that 374 flavanols are in low concentration - if any- within the cuticle but are present in the first cell 375 layers underneath (Figure 3).

The red-skinned Douce Moën and the yellow-skinned Guillevic cider apples were 377 used as model fruits to help distinguish phenolic compound locations by their 378 autofluorescence. Douce Moën is known to be richer in hydroxycinnamic acids and in 379 monomeric tannins, such as (+) catechin, (-) epicatechin and procyanidin with lower tannin 380 degrees of polymerization compared to Guillevic [59]. Anthocyanins were not characterized 381 in the two varieties, but the more colourful Douce Moën skin evidenced higher anthocyanin 382 and/or pigment contents than that of Guillevic. Based on distinct fluorescent emissions of 
reference compounds after $275 \mathrm{~nm}$ excitation, autofluorescence in Douce Moën and Guillevic cryo-sections allowed the detection of pigments in the sub-cuticular cell layers in agreement with the known flavanols, anthocyanins and chlorophyll concentrations in apple skin $[60,61]$. The main distribution of tannins in the sub-cuticular area together with that of phenolic acids in the outer cortex parenchyma may be related to the ratio reported for procyanidin (PC) and hydroxycinnamic acid (HC) concentrations in the fresh peel (HC/PC: 0.68) and parenchyma (HC/PC: 1.29)[62]. This different distribution was not reported in the literature for grape in which flavanols were mainly localized in the epidermis and in the seeds although hydroxycinnamic acid content was higher in skin than in pulp $[16,54,63]$.

Changes in phenolic compounds distribution were not observed with storage modalities that were aimed at impacting apple ripening. This result is at odds with studies showing phenolic compound variations during ripening of fruit [7], such as apple [52,64] and grape $[10,65]$. The lack of autofluorescence discrimination between ripening stages may be related to the small tissue area observed. Instead, the present study evidenced a variation in phenolic distribution between apple varieties. This may be related to different tissue thicknesses as for both varieties, different rupture points in phenolic distributions were observed along distance profiles from the cuticle. These ruptures could correspond to different cell layers in the epidermis and the outer cortex. In particular, a rupture was discernible in fluorescence profiles at an approximately $100 \mu \mathrm{m}$ depth from the skin samples. Apple histology studies have shown changes from smaller cells in the epidermis to larger cells in the outer cortex parenchyma tissue at an approximately $100-\mu \mathrm{m}$ depth from the surface of mature fruit [66-68]. Thus, differences in phenolic compound distribution between the two varieties could reveal genetically distinct thicknesses of epidermal cell layers as well as different secondary metabolism in these tissues. 


\section{Conclusion}

408

409

410

411

412

The cryo-method used here could benefit from further developments in sample preparation and means of cryo-multispectral fluorescence observations. Applying microwaves during cryo-fixation [69] to avoid ice crystal growth combined with the use of confocal microscope stages and lenses for high-resolution cryo-observations [26, 27] is expected to improve the localization of phenolic compounds in the cell and cell wall. Nevertheless, multispectral fluorescence cryo-imaging at $275 \mathrm{~nm}$ excitation allowed the distinction of three major classes of phenolic compounds in tissue under in-vivo-like conditions without any specific dyes. The detection of hydroxycinnamic acids in apple and grape cell walls requires their identification and linkage in the walls. Coupling multispectral analysis based on LSCM observations in the UV-visible wavelength and synchrotron deep-UV analysis could provide a convenient way to extend the range of accessible autofluorescent phenolic compound distributions in the same sample tissue section. These observations will enable other studies on the mechanical behaviour resulting from the presence of these compounds in fruit tissues in the context of fruit development, quality and processing.

\section{Acknowledgements}

Part of this work was realized and supported under the proposal number 20170043 at synchrotron SOLEIL. This work was also supported in part by the Food for Tomorrow programme from the Region Pays de la Loire.

\section{Appendix A: Supplementary data}

Supplementary data associated with this article can be found, in the online version. 


\section{Legend to Figures}

431 Figure 1: Generic phenolic compound structures. $-\mathrm{R}$ may correspond to $-\mathrm{H},-\mathrm{OH}$ or $-\mathrm{OCH}_{3}$ and $-\mathrm{X}$ may correspond to $-\mathrm{H}$ in monomeric form or other flavanol units in polymeric form

433 (Vermerris and Nicholson 2006).

434

Figure 2: Local retail store fresh apple and grape autofluorescence at natural $\mathrm{pH}$ and at $\mathrm{pH}=10.1$ after excitation at $375 \mathrm{~nm}$. The fluorescence emissions recorded are 400-450 nm (blue), 500-530 nm (green), 560-600 nm (yellow), and 630-700 nm (red). C: cuticle, CW: cell wall, Chl: chlorophyll residues, Flv: flavonols. Scale bar: $20 \mu \mathrm{m}$.

Figure 3: Frozen apple autofluorescence for one replicate of Douce Moën and Guillevic at harvest after excitation at $275 \mathrm{~nm}$. Tissue regions are drawn on the right image resulting from a combination of whole Guillevic filter emission images. C: cuticle, CW: cell wall, Scale bar: $40 \mu \mathrm{m}$.

Figure 4: Principal component analysis on the six emission filter images for one replicate of Douce Moën (blue character and arrows) and Guillevic (black character and arrows) at harvest and the PCA images of the four components. On the component images, blue and red pixels represent negative and positive contributions of the emission filters to the component. RGB reconstructed images from PCA components were built from dimension 1 (blue), dimension 2 (red) and dimension 3 (green). C: cuticle, CW: cell wall

Figure 5: Smoothed (LOESS method: $\alpha=0.4$ ) and normalized average plot profiles of Douce Moën (DM) and Guillevic (GU) signal acquisition for emission filters 300 nm, $327 \mathrm{~nm}, 420$ $\mathrm{nm}$ and $600 \mathrm{~nm}$ after excitation at $275 \mathrm{~nm}$. The dotted lines represent the $95 \%$ confidence interval. The coloured areas correspond to significant differences between DM and GU with a p-value $<0.01$ by Student's test $(n=9)$.

Figure 6: Superposed smoothed (LOESS method: $\alpha=0.4$ ) and normalized average plot profiles of Douce Moën and Guillevic signal acquisition for emission filters $300 \mathrm{~nm}$ (grey 
455 line), $327 \mathrm{~nm}$ (green line), $420 \mathrm{~nm}$ (blue line) and $600 \mathrm{~nm}$ (red line) after excitation at 275

$456 \mathrm{~nm}$. The profiles were plotted along the sample section distance from the outer cuticle to 400 $457 \mu \mathrm{m}$ deep inside the tissue.

458 
459 Table 1: Fluorescence excitation/emission maxima of phenolic compounds registered by

460 spectrofluorometry: regular case: literature, bold case: this study.

\begin{tabular}{|c|c|c|c|c|c|}
\hline Compounds & $\begin{array}{l}\lambda_{\text {max excitation }} \\
\quad(\mathbf{n m})\end{array}$ & $\lambda_{\max \text { emission }}$ & Compounds & $\begin{array}{l}\lambda_{\text {max excitation }} \\
\quad(\mathbf{n m})\end{array}$ & $\begin{array}{c}\lambda_{\text {max emission }} \\
(\mathbf{n m})\end{array}$ \\
\hline \multicolumn{3}{|c|}{ Emission range $(<350 \mathrm{~nm})$} & \multicolumn{3}{|c|}{ Emission range (400-500nm) } \\
\hline \multicolumn{3}{|c|}{ Protein group } & \multicolumn{3}{|c|}{ Phenolic acids group } \\
\hline Phenylalanin[70] & 258 & 285 & Ferulic acid & $310 / 370$ & 420 \\
\hline Tyrosin [70] & 276 & 302 & p-Coumaric acid & 350 & 420 \\
\hline \multicolumn{3}{|c|}{ Emission range $(300-400 \mathrm{~nm})$} & Caffeic acid & $270 / 360$ & 440 \\
\hline \multicolumn{3}{|c|}{ Flavanols group } & Chlorogenic acid & 360 & 460 \\
\hline (-) Epicatechin & 290 & 320 & \multicolumn{3}{|c|}{ Others compounds } \\
\hline (+) Catechin & 290 & 320 & Kaempferol[21] & 268 & 422 \\
\hline Procyanidin B1 & 285 & 320 & Rutin & 300 & 460 \\
\hline Procyanidin B2 & 295 & 320 & \multicolumn{3}{|c|}{ Emission range (500-600nm) } \\
\hline Epigallocatechin & 275 & 320 & \multicolumn{3}{|c|}{ Flavonols group } \\
\hline \multicolumn{3}{|c|}{ Others compounds } & Anthocyanins[22] & $300 / 410$ & $360 / 420 / 530$ \\
\hline Tryptophan [22] & 280 & 357 & Cyanidin hydrate & 278 & 550 \\
\hline $\begin{array}{l}2,5- \\
\text { Dihydroxybenzaldehyde[21] }\end{array}$ & 278 & 360 & Quercetin-3-O-glucoside & $260 / 410$ & 510 \\
\hline Syringic acid & 310 & 360 & Quercetin & 420 & 520 \\
\hline Vanillic acid[21] & 278 & 360 & Quercetin galactoside & 295 & 600 \\
\hline Gallic acid & 320 & 370 & Others compounds & & \\
\hline Myricetin[21] & 268 & 370 & Arbutin & 420 & 530 \\
\hline \multirow[t]{2}{*}{ Resveratrol } & $310 / 360$ & 390 & Phloridzin & $250 / 330$ & 540 \\
\hline & & & Chlorophyll/chloroplast[37] & 360 & 680 \\
\hline
\end{tabular}

461 
464 [1] W. Vermerris, R. Nicholson, Phenolic compound biochemistry, Springer, Dordrecht, The 465 Netherlands, 2006.

466 [2] A. Solovchenko, M. Merzlyak, Optical properties and contribution of cuticle to UV 467 protection in plants: experiments with apple fruit, Photoch Photobio Sci, 2 (2003) 861-866.

468 [3] A. Edreva, The importance of non-photosynthetic pigments and cinnamic acid derivatives 469 in photoprotection, Agriculture, ecosystems \& environment, 106 (2005) 135-146.

470 [4] G. Williamson, The role of polyphenols in modern nutrition, Nutr Bull, 42 (2017) 226471235.

472 [5] J.W. Finley, W.J. Hurst, C.Y. Lee, Principles of food chemistry, 4th edition ed., Springer, 4732018.

474 [6] J. Kschonsek, T. Wolfram, A. Stockl, V. Bohm, Polyphenolic compounds analysis of old 475 and new apple cultivars and contribution of polyphenolic profile to the in vitro antioxidant 476 capacity, Antioxidants (Basel), 7 (2018).

477 [7] J.-J. Macheix, Fruit Phenolics, CRC press, 2018.

478 [8] G.L. Lees, N.H. Suttill, K.M. Wall, T.H. Beveridge, Localization of condensed tannins in 479 apple fruit peel, pulp, and seeds, Can. J. Bot., 73 (1995) 1897-1904.

480 [9] K. Amrani Joutei, Y. Glories, M. Mercier, Localisation des tanins dans la pellicule de baie 481 de raisin, VITIS, 33 (1994) 133-138.

[10] Y. Cadot, M. Chevalier, G. Barbeau, Evolution of the localisation and composition of phenolics in grape skin between veraison and maturity in relation to water availability and some climatic conditions, J. Sci. Food Agric., 91 (2011) 1963-1976.

[11] F.B. Essig, A Systematic histological study of palm fruits. I. The Ptychosperma Alliance, 486 Systematic Botany, 2 (1977) 151-168.

[12] K. Yonemori, M. Oshida, A. Sugiura, Fine structure of tannin cells in fruit and callus tissues of persimmon, Acta Hort., 436 (1997) 403-416.

[13] L. Raymond, B. Schaffer, J.K. Brecht, J.H. Crane, Internal breakdown in mango fruit: symptomology and histology of jelly seed, soft nose and stem-end cavity, Postharvest Biol. Technol., 13 (1998) 59-70.

[14] H. Hammouda, C. Alvarado, B. Bouchet, J. Kalthoum-Chérif, M. Trabelsi-Ayadi, S. Guyot, Tissue and cellular localization of tannins in tunisian dates (Phoenix dactylifera 1.) by light and transmission electron microscopy, J. Agric. Food Chem., 62 (2014) 6650-6654.

[15] U. Mayr, S. Michalek, D. Treutter, W. Feucht, Phenolic compounds of apple and their relationship to scab resistance, J Phytopathol, 145 (1997) 69-75.

[16] Y. Cadot, M.T. Miñana Castelló, M. Chevalier, Flavan-3-ol compositional changes in grape berries (Vitis vinifera L. cv Cabernet Franc) before veraison, using two complementary 500563 (2006) 65-75. 

microscopy of diffusible plant compounds, Plant Methods, 14 (2018) 89. Mosselmans, S.P. McGrath, C. Grovenor, F.J. Zhao, Combined NanoSIMS and synchrotron $\mathrm{X}$-ray fluorescence reveal distinct cellular and subcellular distribution patterns of trace elements in rice tissues, New Phytol, 201 (2014) 104-115.

[20] P.J. Harris, R.D. Hartley, Detection of bound ferulic acid in cell walls of the Gramineae 511 by ultraviolet fluorescence microscopy, Nature, 259 (1976) 508.

[21] M.A. Rodríguez-Delgado, S. Malovaná, J.P. Pérez, T. Borges, F.J. García Montelongo, Separation of phenolic compounds by high-performance liquid chromatography with absorbance and fluorimetric detection, J. Chromato. A, 912 (2001) 249-257.

[22] R. Drabent, B. Pliszka, T. Olszewska, Fluorescence properties of plant anthocyanin pigments. I. Fluorescence of anthocyanins in Brassica oleracea L. extracts, Journal of Photochemistry and Photobiology B: Biology, 50 (1999) 53-58.

[23] S. Gómez-Alonso, E. García-Romero, I. Hermosín-Gutiérrez, HPLC analysis of diverse grape and wine phenolics using direct injection and multidetection by DAD and fluorescence, Journal of Food Composition and Analysis, 20 (2007) 618-626. fluorescence spectroscopy: A new tool for control in the wine industry, Journal of Food Composition and Analysis, 24 (2011) 257-264.

[25] M. Corcel, M.-F. Devaux, F. Guillon, C. Barron, Comparison of UV and visible autofluorescence of wheat grain tissues in macroscopic images of cross-sections and particles, Computers and Electronics in Agriculture, 127 (2016) 281-288.

[26] M. Nahmani, C. Lanahan, D. DeRosier, G.G. Turrigiano, High-numerical-aperture cryogenic light microscopy for increased precision of superresolution reconstructions, Proc Natl Acad Sci U S A, 114 (2017) 3832-3836.

[27] R. Faoro, M. Bassu, Y.X. Mejia, T. Stephan, N. Dudani, C. Boeker, S. Jakobs, T.P. Burg, Aberration-corrected cryoimmersion light microscopy, Proc Natl Acad Sci U S A, 115 (2018) 1204-1209.

\section{York, 2006.}

535 [29] A. Giuliani, F. Jamme, V. Rouam, F. Wien, J.-L. Giorgetta, B. Lagarde, O. Chubar, S. 536 Bac, I. Yao, S. Rey, DISCO: a low-energy multipurpose beamline at synchrotron SOLEIL, 537 Journal of Synchrotron Radiation, 16 (2009) 835-841.

538 [30] F. Jamme, S. Kascakova, S. Villette, F. Allouche, S. Pallu, V. Rouam, M. Refregiers, 539 Deep UV autofluorescence microscopy for cell biology and tissue histology, Biol Cell, 105 540 (2013) 277-288.

541 [31] H. Grahn, P. Geladi, K. Esbensen, Multivariate and hyperspectral image analysis, in: 542 Encyclopedia of Analytical Chemistry, John Willey \& Sons, 2016.

543 [32] C.A. Schneider, W.S. Rasband, K.W. Eliceiri, NIH Image to ImageJ: 25 years of Image 544 Analysis, Nature methods, 9 (2012) 671-675.

545 [33] A.A. Neves, E.J. Silva, J.M. Roter, F.G. Belladona, H.D. Alves, R.T. Lopes, S.

546 Paciornik, G.A. De-Deus, Exploiting the potential of free software to evaluate root canal 
biomechanical preparation outcomes through micro-CT images, International Endodontic

548 Journal, 48 (2015) 1033-1042.

549 [34] R Core Team, R: A language and environment for statistical computing, in, $\mathrm{R}$

550 Foundation for Statistical Computing, http://www.R-project.org, Vienna, Austria, 2014.

551

552

553

554

555

556

557

558

559

560

561

562

563

564

565

566

567

568

569

570

571

572

573

574

575

576

577

578

579

580

581

582

583

584

585

586

587

588

[35] J.A. Considine, R.B. Knox, Development and histochemistry of the cells, cell-walls, and cuticle of the dermal system of fruit of the grape, Vitis-vinifera L, Protoplasma, 99 (1979) 347-365.

[36] P. Hutzler, R. Fischbach, W. Heller, T.P. Jungblut, S. Reuber, R. Schmitz, M. Veit, G. Weissenböck, J.-P. Schnitzler, Tissue localization of phenolic compounds in plants by confocal laser scanning microscopy, J. Exp. Bot., 49 (1998) 953-965.

[37] J.I. García-Plazaola, B. Fernández-Marín, S.O. Duke, A. Hernández, F. López-Arbeloa, J.M. Becerril, Autofluorescence: Biological functions and technical applications, Plant Sci., 236 (2015) 136-145.

[38] F.W.J. Teale, G. Weber, Ultraviolet fluorescence of the aromatic amino acids, Biochem. J., 65 (1957) 476-482.

[39] A.H. Moskowitz, G. Hrazdina, Vacuolar contents of fruit subepidermal cells from Vitis species, Plant Physiol., 68 (1981) 686-692.

[40] S. Kitamura, Transport of flavonoids: from cytosolic synthesis to vacuolar accumulation, in: E. Grotewold (Ed.) The science of flavonoids, Springer, 2006, pp. 123-146.

[41] C. Le Bourvellec, K. Bouzerzour, C. Ginies, S. Regis, Y. Ple, C.M.G.C. Renard, Phenolic and polysaccharidic composition of applesauce is close to that of apple flesh, Journal of Food Composition and Analysis, 24 (2011) 537-547.

[42] C.M.G.C. Renard, A.A. Watrelot, C. Le Bourvellec, Interactions between polyphenols and polysaccharides: Mechanisms and consequences in food processing and digestion, Trends in Food Science \& Technology, 60 (2017) 43-51.

[43] S. Gagné, C. Saucier, L. Gény, Composition and cellular localization of tannins in cabernet sauvignon skins during growth, J. Agric. Food Chem., 54 (2006) 9465-9471.

[44] S. Chassagne-Berces, C. Poirier, M.F. Devaux, C. Fonseca, M. Lahaye, G. Pigorini, C. Girault, M. Marin, F. Guillon, Changes in texture, cellular structure and cell wall composition in apple tissue as a result of freezing, Food Res. Int., 42 (2009) 788-797.

[45] S. Guyot, N. Marnet, P. Sanoner, J. Drilleau, Variability of the polyphenolic composition of cider apple (Malus domestica) fruits and juices, J Agric Food Chem, 51 (2003) 6240 6247.

[46] P. Mattila, J. Hellström, R. Törrönen, Phenolic acids in berries, fruits, and beverages, J. Agric. Food Chem., 54 (2006) 7193-7199.

[47] J. Lee, B.L. Chan, A.E. Mitchell, Identification/quantification of free and bound phenolic acids in peel and pulp of apples (Malus domestica) using high resolution mass spectrometry (HRMS), Food Chem, 215 (2017) 301-310.

[48] P. Albersheim, A. Darvill, K. Roberts, R. Sederoff, A. Staehelin, Plant cell walls, Garland Sciences, New York, 2011.

[49] S.C. Fry, Phenolic components of the primary cell wall. Feruloylated disaccharides of Dgalactose and L-arabinose from spinach polysaccharides, Biochem. J., 203 (1982) 493-504. 
[50] L. Saulnier, J.F. Thibault, Ferulic acid and diferulic acids as components of sugar-beet pectins and maize bran heteroxylans, J. Sci. Food Agric., 79 (1999) 396-402.

[51] S. Fernández, S. Osorio, A. Heredia, Monitoring and visualising plant cuticles by confocal laser scanning microscopy, Plant Physiol. Biochem., 37 (1999) 789-794.

[52] M. Awad, A. de Jager, L. van der Plas, A. van der Krol, Flavonoid and chlorogenic acid changes in skin of Elstar and Jonagold apples during development and ripening, Scientia Hort, 90 (2001) 69 - 83.

[53] S. Khanizadeh, R. Tsao, D. Rekika, R. Yang, M.T. Charles, H.P. Vasantha Rupasinghe, Polyphenol composition and total antioxidant capacity of selected apple genotypes for processing, Journal of Food Composition and Analysis, 21 (2008) 396-401.

[54] G. Di Lecce, S. Arranz, O. Jáuregui, A. Tresserra-Rimbau, P. Quifer-Rada, R.M. Lamuela-Raventós, Phenolic profiling of the skin, pulp and seeds of Albariño grapes using hybrid quadrupole time-of-flight and triple-quadrupole mass spectrometry, Food Chem., 145 (2014) 874-882.

[55] R.M. Bostock, S.M. Wilcox, G. Wang, J.E. Adaskaveg, Suppression of Monilinia fructicola cutinase production by peach fruit surface phenolic acids, Physiol. Mol. Plant Pathol., 54 (1999) 37-50.

[56] M. Grotte, F. Duprat, D. Loonis, E. Pietri, Mechanical properties of the skin and the flesh of apples, International Journal of Food Properties, 4 (2001) 149-161.

[57] H. Bargel, K. Koch, Z. Cerman, C. Neinhuis, Evans Review No. 3: Structure-function relationships of the plant cuticle and cuticular waxes - a smart material?, Functional Plant Biology, 33 (2006) 893.

[58] B.P. Khanal, M. Knoche, Mechanical properties of cuticles and their primary determinants, J. Exp. Bot., 68 (2017) 5351-5367.

[59] P. Sanoner, S. Guyot, N. Marnet, D. Molle, J.F. Drilleau, Polyphenol profiles of french cider apple varieties (Malus domestica sp.), J. Agric. Food Chem., 47 (1999) 4847-4853.

[60] E.A. Veraverbeke, N. Van Bruaene, P. Van Oostveldt, B.M. Nicolai, Non destructive analysis of the wax layer of apple (Malus domestica Borkh.) by means of confocal laser scanning microscopy, Planta, 213 (2001) 525-533.

[61] R.-N. Bae, K.-W. Kim, T.-C. Kim, S.-K. Lee, Anatomical observations of anthocyanin rich cells in apple skins, Hortscience, 41 (2006) 733-736.

[62] S. Guyot, N. Marnet, D. Laraba, P. Sanoner, J.-F. Drilleau, Reversed-Phase HPLC following thiolysis for quantitative estimation and characterization of the four main classes of phenolic compounds in different tissue zones of a french cider apple variety (Malus domestica Var. Kermerrien), J. Agric. Food Chem., 46 (1998) 1698-1705.

[63] Y. Cadot, M.T. Miñana-Castelló, M. Chevalier, Anatomical, histological, and histochemical changes in grape seeds from Vitis vinifera L. cv cabernet franc during fruit development, J. Agric. Food Chem., 54 (2006) 9206-9215.

[64] M. Murata, M. Tsurutani, M. Tomita, S. Homma, K. Kaneko, Relationship between apple ripening and browning: changes in polyphenol content and polyphenol oxidase, J. Agric. Food Chem., 43 (1995) 1115-1121.

[65] R. Delgado, P. Martín, M. del Álamo, M.R. González, Changes in the phenolic composition of grape berries during ripening in relation to vineyard nitrogen and potassium fertilisation rates, J. Sci. Food Agric., 84 (2004) 623-630. 
633 [66] H.P. Bell, The protective layers of the apple, Canadian Journal of Research, 15c (1937) 634 391-402.

635 [67] H.B. Tukey, J.O. Young, Gross morphology and histology of developing fruit of the 636 apple, Botanical Gazette, 104 (1942) 3 - 25.

637 [68] B.P. Khanal, M. Knoche, Mechanical properties of apple skin are determined by 638 epidermis and hypodermis, J. Am. Soc. Hortic. Sci., 139 (2014) 139-147.

639 [69] E. Xanthakis, A. Le-Bail, H. Ramaswamy, Development of an innovative microwave 640 assisted food freezing process, Innovative Food Science \& Emerging Technologies, 26 (2014) 641 176-181.

642 [70] J. Christensen, L. Nørgaard, R. Bro, S.B. Engelsen, Multivariate autofluorescence of 643 intact food systems, Chemical Reviews, 106 (2006) 1979-1994. 


\section{Phenolics acids}<smiles>[R]c1cc(C(=O)O)c([R])c([R])c1[R]</smiles>

Hydroxybenzoic acids

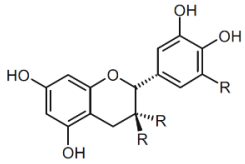

Flavanols

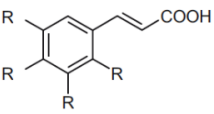

Hydroxycinnamic acids

Flavonoids<smiles>[R]c1cc(C2Oc3cc(O)cc(O)c3C(=O)C2O)cc([R])c1O</smiles>

Flavonols<smiles></smiles>

Anthocyanidins 


\section{$\mathrm{pH}$ native}

pH 10.1
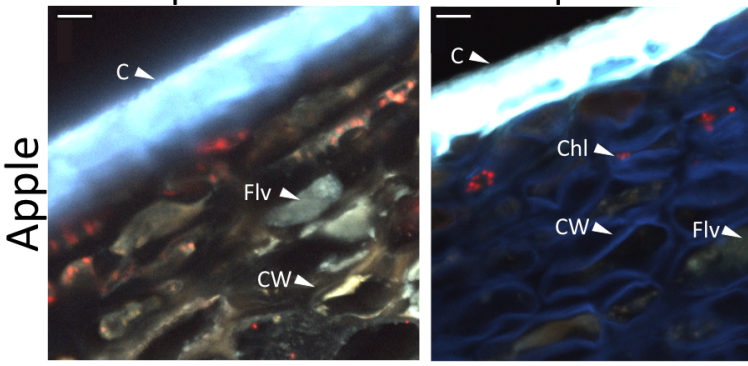

CA

(1)

요

T

1

(1)

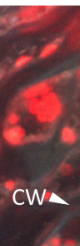

Chl

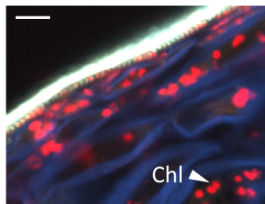

CWA

\section{$\mathrm{Chl} \Delta, \mathrm{e}$}

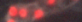



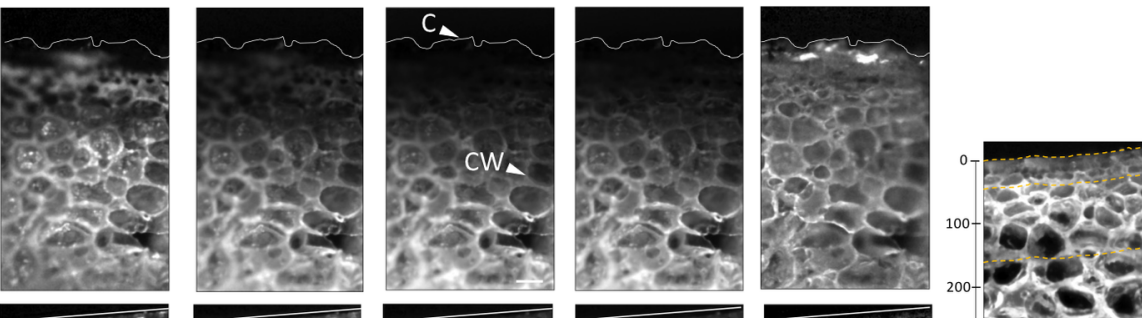

Cuticle

Sub-cuticle

Epidermis

$\frac{\bigcup}{\frac{U}{亠}}$
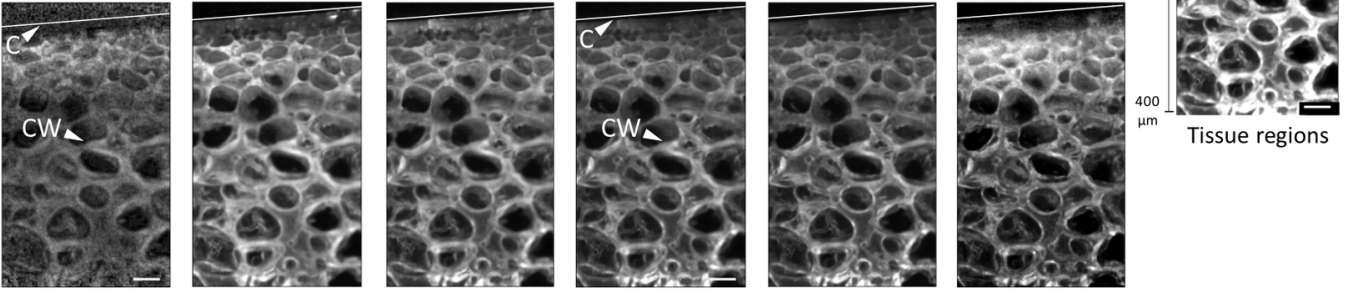

Outer-cortex

Tissue regions 
DM vs GU: filter $300 \mathrm{~nm}$

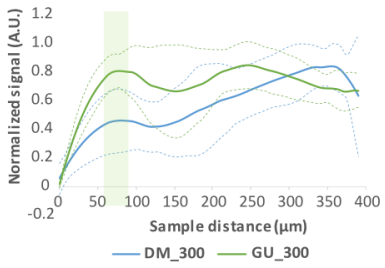

\section{DM vs GU: filter $420 \mathrm{~nm}$}

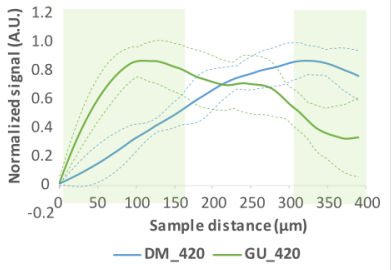

DM vs GU: filter $327 \mathrm{~nm}$

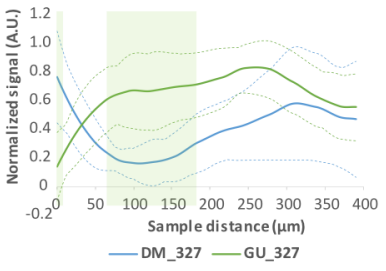

\section{$D M$ vs GU: filter $600 \mathrm{~nm}$}

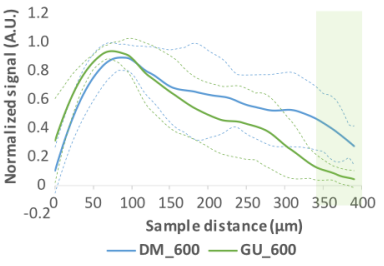


